\title{
A GRAVIDEZ COMO DURAÇÃO: UMA LEITURA BERGSONIANA DO FILME OLMO E A GAIVOTA
}

\author{
Pregnancy as a duration: a Bergsonian reading of the movie Olmo and the \\ seagull
}
El embarazo como la duración: una lectura bergsoniana de la película Olmo y la gaviota

Tatiane Leal

Pós-doutoranda no Instituto Nacional de Comunicação Pública da Ciência e Tecnologia (INCT-CPCT) da Fundação Oswaldo Cruz (Fiocruz)

tatianeclc@gmail.com

\section{Resumo}

Este artigo traz uma análise do filme-documentário Olmo e a gaivota, de Petra Costa e Lea Glob, com base na filosofia de Henri Bergson. A partir da experiência da gestação da atriz Olivia Corsini, narrada cinematograficamente, a gravidez pode ser compreendida como uma duração, no sentido bergsoniano. Analisando o filme como um discurso, proponho que este produto cinematográfico traz a invenção da gestação enquanto um tempo indivisível e contínuo, permeado por modulações de afetos, contrariando a perspectiva dominante na contemporaneidade que entende a gestação como um período que deve ser meticulosamente quantificado e medicalizado. Assim, o filme oferece uma janela oportuna para refletir como Bergson estabelece uma perspectiva filosófica fundamental para compreender o modo como experimentamos o tempo e a forma como o inventamos em produtos culturais como o cinema. Palavras-chave: Olmo e a gaivota. Representação da gravidez. Bergson.

\begin{abstract}
This paper features an analysis based on the philosophy of Henri Bergson of the documentary film Olmo and the seagull, by Petra Costa and Lea Glob. From the portrait of the gestation of the actress Olivia Corsini, narrated cinematographically, the pregnancy can be understood as a duration, in the Bergsonian sense. Analyzing the film as a discourse, I propose that this cinematographic product brings the invention of gestation as an indivisible and continuous time, permeated by modulations of affections, contrary to the dominant perspective in contemporaneity that understands pregnancy as a period that must be meticulously quantified and medicalized. Thus, the film provides a convenient window to reflect on how Bergson establishes a fundamental philosophical perspective to understand how we experience time and how we invent it in cultural products such as cinema.
\end{abstract}

Key words: Olmo and the seagull. Pregnancy representation. Bergson.

\section{Resumen}


En este artículo se presenta un análisis del documental Olmo y la gaviota, de Petra Costa y Lea Glob, basado en la filosofía de Henri Bergson. A partir de la experiencia del embarazo de la actriz Olivia Corsini, dijo cinematográficamente, el embarazo puede ser entendido como una duración en el sentido bergsoniano. Em un análisis de la película como un discurso, propongo que este producto cinematográfico trae a la invención del embarazo como un tiempo indivisible y continuo, permeado por modulaciones de afectar, en contra de la opinión predominante en contemporánea que entiende el embarazo como un periodo que debe ser cuantificado y medicalizado a fondo. Así, la película ofrece una ventana oportuna para reflejar cómo Bergson establece una perspectiva filosófica fundamental para entender la forma en que experimentamos el tiempo y la forma en que lo podemos inventar en los productos culturales como películas.

Palabras clave: Olmo y la gaviota. Representación del embarazo. Bergson.

\section{INTRODUÇÃO}

Lançado em 2015, o filme-documentário Olmo e a Gaivota, de Petra Costa e Lea Glob, explora os pensamentos e as sensações experimentados pela atriz italiana Olivia Corsini durante sua gravidez. Às vésperas de representar a personagem Arkádina na peça A Gaivota, de Tchekov, Olivia e seu companheiro, o ator francês Serge Nicolaï, descobrem que estão esperando seu primeiro filho. A gestação revela-se de risco, obrigando Olivia a permanecer em casa durante todo o período, afastando-a dos palcos e confrontando-a com uma miríade de sentimentos que, nas representações hegemônicas, não costumam ser associados à gravidez, como tédio, vazio, agressividade e solidão.

O filme, que ganhou o prêmio de melhor documentário no Festival do Rio de 2015, teve como motivação, segundo a diretora brasileira Petra Costa, preencher o vazio das representações cinematográficas sobre a gravidez como um percurso psicológico feminino ${ }^{1}$. Ao partir do ponto de vista da gestante e de seus conflitos internos, o filme apresentaria uma visão da gestação com matizes menos definidos do que o estereótipo frequentemente difundido na cultura e reforçado por uma série de produtos midiáticos, que definiria esse período como de plena felicidade e realização para a mulher (REZENDE, 2011).

No que diz respeito a seus aspectos formais, Olmo e a gaivota transita entre ficção e documentário: Olivia Corsini, de fato, estava grávida, e teve sua rotina acompanhada e registrada pela equipe de gravação. Ao mesmo tempo, a atriz não deixou de ser dirigida nas

\footnotetext{
${ }^{1}$ Petra Costa discorre sobre o assunto em entrevistas como as disponíveis em: http://epoca.globo.com/vida/noticia/2015/11/petra-costa-temos-uma-tolerancia-doentia-com-falta-de-respeitomulheres.html e http://revistatrip.uol.com.br/tpm/petra-costa-diretora-de-olmo-e-a-gaivota-nas-paginasvermelhas. Acesso em: 10 set. 2019.
} 
filmagens, seja ao ser interpelada a anotar e explicitar pensamentos e sentimentos sobre sua condição, seja ao efetivamente atuar em determinadas cenas, como o momento em que ela descobre que será mãe - gravado a posteriori - e a interpretação de um diálogo em que ela e seu marido representam, a pedido das diretoras, diferentes pontos de vista sobre a gestação.

Para além dos sentidos que circulam em torno da gravidez retratada no filme, um elemento se destaca em sua narrativa: a temporalidade. Contrariando a perspectiva médica dominante na contemporaneidade, em que a gestação é vista como um período de monitoramento (ARNEY apud CHAZAN, 2005) que precisa ser meticulosamente quantificado e acompanhado por meio de uma contagem semanal, proponho neste artigo que Olmo e a gaivota traz uma perspectiva da gravidez como duração no sentido bergsoniano. A partir de uma leitura inspirada por Matéria e memória (BERGSON, 1999), analiso este produto cinematográfico e a possibilidade de uma invenção da gravidez enquanto um tempo indivisível e contínuo, permeado por modulações de afetos. Não se pretende, neste artigo, analisar o cinema em seus aspectos técnicos, mas ler o filme Olmo e a gaivota enquanto discurso, no sentido foucaultiano (FOUCAULT, 2011). Seus diálogos, suas cenas e recursos sonoros e visuais integram uma narrativa que engendra uma subjetividade feminina e um modo de viver a gravidez.

\section{PERCEPÇÃO, AFECÇÃO E MEMÓRIA EM BERGSON}

Para compreender os sentidos da gravidez em Olmo e a gaivota a partir de uma leitura bergsoniana, é necessário expor alguns de seus conceitos. O filósofo francês Henri Bergson ([1896] 1999) apresenta, no livro Matéria e Memória, uma reflexão sobre o tempo a partir de uma perspectiva ontológica. Ele rompe com a tradição filosófica e científica de sua época acerca da memória e das formas de perceber o mundo. Bergson estabelece um diálogo direto com o dualismo presente na tradição filosófica entre materialismo e idealismo, entendendo a matéria e suas representações no pensamento a partir de uma nova perspectiva.

Por um lado, o idealismo subjetivista de Kant postulava que não é possível dizer o que as coisas são, e sim apenas como elas aparecem ao sujeito, ou seja, a matéria é a representação que temos dela. $\mathrm{O}$ espírito - pensado aqui como consciência - determinaria, então, a existência das coisas. O problema, nessa tradição filosófica, seria: como falar de algo que está fora de mim? Por outro lado, o realismo materialista aposta na pura materialidade das coisas. Até mesmo a consciência seria um epifenômeno material, uma fosforescência 
produzida pelo cérebro, encerrada em um mistério, até então, não resolvido pela filosofia (BERGSON, 1999).

Bergson ultrapassa essa dicotomia criando um novo dualismo entre matéria e memória. Ele define a matéria como um conjunto de imagens, rompendo também com o platonismo, que as entendia como pálidas sombras do mundo das ideias (PLATÃO, 2007). É importante ressaltar que o termo imagem em Bergson difere da ideia de representação iconográfica da semiologia. Nas palavras do filósofo, “por 'imagem' entendemos uma certa existência que é mais do que aquilo que o idealista chama de representação, porém menos do que aquilo que o realista chama uma coisa - uma existência situada a meio caminho entre a “coisa' e a 'representação"” (BERGSON, 1999, p. 1-2).

A matéria seria então esse conjunto de imagens, as quais agiriam umas sobre as outras. O corpo é, ele próprio, uma imagem, que constitui um centro de ação, orientado a partir da percepção do próprio ser e das imagens que o cercam. Bergson tem uma perspectiva fenomenológica: não existe percepção humana sem a mediação de seu próprio corpo, marcado pelas afecções. O corpo é uma imagem que prevalece sobre as demais na medida em que não o conheço apenas a partir de percepções (externas), mas por afecções (internas).

Os conceitos de percepção e afecção são fundamentais para entender os modos de concepção do tempo na filosofia bergsoniana. Em mais um rompimento com a tradição filosófica de sua época, Bergson afirma que o homem percebe o mundo não para contemplálo ou conhecê-lo, mas de forma vitalmente interessada: ele percebe para agir. Desse modo, haveria uma diferença de grau, e não de natureza, entre matéria e percepção. Nas palavras de Bergson (1999, p. 35), “[a] realidade da matéria consiste na totalidade de seus elementos e de suas ações de todo tipo. Nossa representação da matéria é a medida de nossa ação possível sobre os corpos; ela resulta da eliminação daquilo que não interessa nossas necessidades".

A percepção seria, assim, uma potência incluída no conjunto de imagens possíveis que constitui a matéria. Empobrecemos a matéria para perceber nela somente a face que se volta à nós em um sentido vitalmente interessante, no que diz respeito às promessas e ameaças que nos rondam. Como afirma Deleuze $(1999$, p. 16, grifos do original), (...) a percepção não é o objeto mais algo, mas o objeto menos algo, menos tudo o que não nos interessa”. Perceber é, assim, uma atitude vital, percebemos para viver (TUCHERMAN, 2016).

Assim, as imagens exteriores influem sobre o corpo lhe transmitindo movimento; este, por sua vez, influi sobre elas lhes restituindo movimento. O corpo é, desse modo, um centro de ação. A diferença é que a forma com que as imagens não-humanas exercem influência é 
calculável pelas leis da natureza, não há a noção de escolha. Por sua vez, o corpo pode exercer sobre as outras imagens uma influência real, já que pode/deve decidir entre várias ações materialmente possíveis. Os objetos que cercam o corpo refletem a sua ação possível sobre eles: ou seja, suas cores, contornos e formas mudam conforme estou mais próximo ou mais distante deles. O corpo deve obter, em meio às coisas que o cercam, a qualidade e a quantidade de movimento necessárias para agir sobre elas.

A percepção do mundo seria necessariamente impregnada de afecções, dois conceitos que se entrelaçam no movimento do ser no mundo. A percepção estaria para a ação virtual assim como a afecção estaria para a ação real; ela constitui um estado interno e vividamente sentido a partir do corpo. Para Bergson (1999, p. 64), "percebo o interior dessa imagem, o íntimo, através de sensações que chamo afetivas, em vez de conhecer apenas, como nas outras imagens, sua película superficial". Percepção e afecção, apesar de se misturarem na ação humana, teriam diferenças de natureza. Enquanto a percepção derivaria do conjunto de imagens que constitui as coisas, que subsiste para além da corporalidade, a afecção não sobrevive quando finda o ser, já que se forma dentro do próprio corpo. Assim, “(...) as sensações, longe de serem os materiais com que a imagem é fabricada, aparecerão como a impureza que nela se mistura, sendo aquilo que projetamos de nosso corpo em todos os outros" (BERGSON, 1999, p. 274).

Partindo dos conceitos de percepção e afecção, Bergson adensa sua reflexão ao estabelecer uma nova ideia de memória, que funda sua concepção sobre o tempo, essencial para a análise empreendida neste artigo. Para o filósofo, não há percepção de fato sem a presença de imagens-lembrança. Ele esquematiza a relação entre percepção e memória a partir da figura de um cone invertido. $O$ vértice seria o ponto mais próximo da percepção, o encontro do meu corpo com o plano material, e a base iria em direção à memória, constituindo a face mais próxima da totalidade aleatória de imagens-lembrança, obtidas a partir da experiência vivida. Nossa experiência no mundo seria um ir e vir pelas dimensões desse cone, em que percepção e memória necessariamente se misturam. É importante ressaltar que essa memória não é pensada em termos de localização espacial, mas como uma espessura temporal ontológica, em que as lembranças existem perenemente em outro plano - o da virtualidade - podendo ser atualizadas a partir de uma contração do passado em direção à percepção do presente.

Ainda a partir desse esquema, tanto o vértice quanto a base do cone seriam conceitos de direito e não de fato; a existência humana se daria a partir de um movimento entre as 
camadas intermediárias desses dois extremos. Percepção e memória seriam distintas por natureza: enquanto a percepção se pensaria a partir da noção de espaço no mundo material, a memória deve ser entendida a partir do tempo, como uma atividade do espírito por excelência. Essa perspectiva rompe com a visão localizacionista da época, que buscava determinar em que espaço do cérebro residia a memória. Ela também refuta a ideia de tempo newtoniano, uma ideia de temporalidade enquanto movimento retilíneo uniforme, a adição de diversos momentos em uma linha contínua em direção ao futuro.

No que diz respeito à filosofia, Bergson apresenta um tempo que se contrapõe ao hábito social de espacializar o tempo, percebê-lo em quantidades específicas. Em nossos relógios, por exemplo, identificamos quantidades de tempo pelos espaços percorridos pelo ponteiro do mostrador. O calendário é outro instrumento criado para dividir a temporalidade em fatias homogêneas - dias, meses, anos - que se somam, produzindo uma ideia de origem (em nosso caso, o calendário gregoriano produz a ideia de antes e depois de Cristo) e um contínuo em direção ao futuro.

Nesse sentido, o desenvolvimento e a consolidação da sociedade capitalista consistiram em condições de possibilidade para a emergência de formas cada vez mais sofisticadas de contar o tempo. Se, em sociedades mais antigas, a temporalidade era definida a partir do movimento do Sol e das estações do ano, os relógios de ponteiro, na modernidade ficam cada vez mais precisos: no século XVII, surge o ponteiro dos minutos e, no XVIII, o dos segundos. A necessidade de contar o tempo das fábricas, convertido em ganhos financeiros, exigiu formas cada vez mais minuciosas de espacializar e de compartimentar o tempo (ROCHA, 2012).

Hoje, para Crary (2013), o regime da performance no capitalismo neoliberal está ligado à emergência de uma temporalidade 24/7, Ele identifica a experiência contemporânea como um tempo mercadológico e financializado, dividido em fatias para a produção e a geração de lucro, que persegue uma existência produtiva sem pausas. A rotina 24/7 anunciaria um tempo sem tempo, sem sequência ou retorno. É a celebração de uma alucinação do presente, que considera que existe somente o que está imediatamente disponível, acessível ou utilizável, promovendo uma ideia de tempo a-histórico, autossuficiente e sem ligação com as raízes do passado.

Entretanto, olhar para a filosofia de Bergson é perceber como essa forma de medir e de espacializar o tempo não dá conta de expressar seus matizes da forma como o corpo o vive. Para Bergson, a vida tem uma temporalidade específica, que pode ser entendida a partir do 
conceito de duração. Nessa concepção o tempo é um fluxo que não cessa de passar. Qualquer divisão espacializada desse espraiamento seria uma abstração, possível apenas em um exercício de contemplação fora do movimento do corpo em sua atenção à vida. No fluxo de consciência, não há separação entre passado, presente e futuro. Essas três dimensões coexistem, formando uma continuidade. A própria ideia de presente seria uma ficção: quando paramos para pensar no momento presente, ele já passou. A ideia de presente se daria a partir da percepção do passado imediato - a sensação - e do futuro imediato - a ação -, portanto, o presente seria, no máximo, sensório-motor. Já o presente concreto, vivido, seria percebido como uma duração, e a memória seria o efeito do atravessamento dos viventes por essa temporalidade.

Segundo Bergson, constituímos memória o tempo todo e vivemos a partir dela, quando, a partir das necessidades da atenção à vida, o passado emerge do plano da virtualidade e em um salto se atualiza, misturando-se à percepção e à afecção e orientando um movimento dentro de um plano virtual de ações possíveis. Existiriam, então, duas formas de existência atual desse passado: a memória hábito e a memória por excelência. Apesar de ambas operarem por meio de lembranças, elas teriam uma diferença de natureza.

O hábito, para Bergson, é uma lembrança adquirida pela repetição de um mesmo esforço. Exige, inicialmente, a decomposição e, depois, a recomposição da ação total. O exercício habitual do corpo armazena-se num mecanismo que estimula por inteiro um impulso inicial, num sistema fechado de movimentos automáticos, evitando que tenhamos que aprender tudo novamente ao desempenhar uma tarefa, como andar de bicicleta ou escovar os dentes. Esses automatismos são como réplicas prontas para perguntas que deixam de ser colocadas.

Já a memória por excelência diz respeito aos acontecimentos da vida; contém, por essência, uma data, um contexto específico, e não pode, consequentemente, repetir-se. Essas lembranças não agem o tempo todo no corpo. Elas estão sempre presentes, mas não conscientes. Às vezes, encontram uma fissura e se atualizam. Pertencem ao que Bergson chama de virtualidade, um plano ontológico que, pertencendo ao espírito, coloca-se para além do mundo material e da ação presente, mas com uma existência real. A partir do salto do passado para o presente, as imagens-lembranças se atualizam, saindo então do virtual.

Assim, enquanto a memória hábito é um passado que age em mim, a memória por excelência é o passado que imagina em mim, através das imagens-lembrança. Somos uma ponta movente do passado em direção ao futuro. A imagem-lembrança seria uma memória 
afetiva, que permitiria que o vivente ocupasse, simultaneamente, dois blocos de tempo, ao transportar o passado como imaginação para o presente, entremeado por afecções. Por conseguinte, o passado imagina em nós porque o recurso da lembrança nos permite ir além da reação por automatismo - podemos refletir, escolher, abrir o centro de indeterminação do corpo diante da variedade de ações possíveis. Em suma, o ser humano seria a síntese atual de todos os seus estados passados, que condicionariam sua ação futura, sem determiná-la.

Enquanto a imagem-lembrança permanece latente na virtualidade, esperando a possibilidade de atualizar-se, o presente escoa a todo momento em um tempo-fluxo. A temporalidade seria, então, vista como movimento, o que também pode ser expresso pelo conceito de devir. Em Deleuze, o devir é uma dimensão “(...) bergsonianamente remetida a um movimento absoluto e contínuo, refere-se a espessuras temporais permanentemente atravessadas por mudanças infinitesimais de ritmos e de vibrações" (FERRAZ, 2016, p. 2-3).

A partir dos conceitos bergsonianos trabalhados nesta breve exposição, faremos, a seguir, uma análise do filme-documentário Olmo e a gaivota. Proponho, nessa reflexão, perceber de que forma esse produto cinematográfico imagina a gravidez como um processo temporal e afetivo, que pode ser entendido a partir da ideia bergsoniana de duração.

\section{AS TEMPORALIDADES EM OLMO E A GAIVOTA}

Em uma das primeiras cenas de Olmo e a gaivota, a atriz Olivia Corsini faz um teste de gravidez de farmácia. Seu marido, o ator Serge Nicolaï, conversa com ela através da porta do banheiro. Ele lhe diz que ela precisa contar dois minutos para que saia o resultado, e tenta adverti-la sobre o modo correto de espaçar os segundos. Ela o interrompe: "Me diz uma música que tenha dois minutos". A espera pelo resultado que confirmaria que Olivia estava à espera do primeiro filho se passou, assim, ao som da música "Mi sono innamorato di te", de Luigi Tenco, cantada pelo casal (OLMO, 2015).

Essa ideia de um tempo vivido e sentido, que recusa a contagem dos relógios, perpassa todo o documentário. Além de "uma travessia pelo labirinto da mente de uma mulher", como afirma a sinopse oficial, ou de um filme sobre a gravidez do ponto de vista da mulher que a experimenta, Olmo e a gaivota pode ser entendido a partir de uma reflexão sobre a temporalidade.

Como uma breve descrição do filme, podemos dizer que ele se estrutura a partir de três momentos: a descoberta da gravidez, repleta de felicidade, e a promessa de uma gestação 
vivida normalmente nos palcos, entre os ensaios da peça A gaivota, de Tchekov. Por causa de um sangramento, o casal procura um hospital e, após o exame de ultrassonografia, Olivia é informada pelo médico que sua gravidez é de risco e ela deve permanecer em casa, em repouso absoluto, sob a ameaça de um aborto espontâneo. A partir daí, começa a sequência mais longa do filme, gravada na casa da atriz, em que suas atividades cotidianas são interpeladas por seus pensamentos em voz alta, transmitidos por gravações em off. Por fim, na reta final do filme, Olivia organiza uma festa com amigos de seu passado para apresentar-se diante deles como uma mulher grávida e, buscar em suas companhias, auxílio para ressignificar sua gestação.

Durante o filme, o corpo de Olivia é o centro de ação a partir do qual acompanhamos movimentos, pensamentos e sentimentos, narrados e realizados diante da câmera. Se, para Bergson, não existe percepção humana sem a mediação do corpo, Olivia experimenta o mundo a partir de sua corporeidade em gestação. Além disso, o foco recai apenas sobre seu próprio corpo. Apesar de haver um feto em formação no útero de Olivia, ela não interage com ele e o espectador não é levado a pensá-lo como um personagem, ao menos não com contornos definidos. Somente na parte final do filme, em uma conversa entre Olivia e Serge sobre nomes, pode-se inferir que a criança tem o sexo masculino, fato que só é confirmado nas cenas após os créditos, em que o bebê aparece. O filme não culmina com o parto, e sim com a festa, ainda na gestação. As imagens do bebê aparecem como um apêndice, um complemento à narrativa que já foi contada.

Em diversos momentos do filme, Olivia discorre sobre sua vida como atriz. Ela acessa a memória para narrar suas experiências, e as lembranças emergem como um contraste colorido e vívido, contraposto a seu tempo presente, imobilizado pela gravidez de risco. Em uma das primeiras cenas após a visita ao hospital, a câmera mostra os detalhes prosaicos da casa, filmando enfeites e bibelôs, Olivia recolhendo as roupas sujas, e os pratos na pia, esperando para serem lavados. Essa tomada é acompanhada pela narração em off:

Quando eu era mais nova, eu tinha a sensação de ser possuída por um animal muito agitado que não achava seu lugar. Por isso, tive que partir. Era essa sensação de insatisfação constante num cotidiano sem graça que me enlouquecia. Sempre em busca de algo onde colocar toda essa energia. Sempre, sempre atuando, atuando, atuando... (OLMO, 2015) ${ }^{2}$.

\footnotetext{
${ }^{2} \mathrm{O}$ filme é feito, majoritariamente, em língua francesa, com um uso frequente do italiano, língua materna de Olívia, além de apresentar alguns diálogos em inglês e espanhol. Optei por utilizar, neste artigo, as traduções dos diálogos citados para o português (tradução livre).
} 
Nesse momento, as lembranças de Olivia não são apenas narradas, mas exibidas em imagens de filmes familiares, contrastadas com as cenas do presente a partir de uma coloração envelhecida. Nelas, uma Olivia mais jovem apresenta extrema vitalidade e movimento, correndo, gesticulando e gargalhando. A narração continua: “...com 4, 5, 6 anos, 7, 25, 32... Fazendo de tudo para ser amada. Mas o importante agora é tentar ficar calma, não se mexer" (OLMO, 2015). Como afirma Deleuze (1999, p. 45), em seu Bergsonismo: “O passado e o presente não designam dois momentos sucessivos, mas dois elementos que coexistem: um, que é o presente e que não para de passar; o outro, que é o passado e que não para de ser, mas pelo qual todos os presentes passam”.

Assim, as lembranças emergem a partir das necessidades de Olivia no presente, que precisa recordar sua identidade como uma mulher atriz, cheia de vitalidade, para enfrentar os momentos de imobilidade requisitados pela vida atual. Desse modo, a evocação das imagenslembrança permite a coexistência das experiências de mobilidade do passado com as do corpo grávido que, aparentemente confinado no repouso, move-se no processo de gestar uma criança e de experimentar afetivamente esse período.

Olivia se vê presa em um mundo de automatismos representado pelas tarefas domésticas realizadas em câmera lenta, sem espaço para a ação livre. Há uma oposição, na montagem das cenas, entre o trabalho reprodutivo doméstico, feito com o auxílio da memóriahábito, e o trabalho do teatro, narrado a partir da memória por excelência. Ao ser encerrada no ambiente do lar, Olivia se demora na percepção das tarefas domésticas. A câmera nos leva a prestar atenção em atos corriqueiros e repetitivos, como lavar os pratos. Diante da ameaça de não retornar ao teatro, Olivia direciona a atenção à vida às atividades que seu corpo lhe permite desenvolver, levando o espectador a contemplar essas tarefas de modo a atribuir-lhes sentidos. Como o filme é pensado a partir do corpo de Olivia como centro de ação, a sensação do tédio é a que mais permeia a exibição dessas atividades, enquanto as narrativas sobre o teatro remetem à alegria e à vitalidade.

Ainda pensando a partir de Bergson, Olivia não quantifica seu tempo de atuação nos palcos, mas experiencia um devir-atriz sentido como uma duração, que atravessa continuamente sua vida e lhe permite perceber o mundo a sua volta também como um fluxo. Somente ao suspender a percepção interessada na atenção à vida, Olivia contempla seu passado e o espacializa, mas não sem deixar transparecer que o que é rememorado foi vivido de forma contínua e indivisível. Em uma cena, ela afirma, como se percebesse pela primeira vez: "Quando cheguei aqui [em Paris], tinha 22 e agora tenho 34" (OLMO, 2015). Ela 
demonstra a perplexidade com a passagem dos anos, vividos sempre atuando, como ela narra em outras duas cenas:

Nesses últimos dez anos, eu trabalhei, trabalhei, trabalhei... vivi no meio de tecidos bordados, cortinas de seda, maquiagem, luzes.... Criava-se dia e noite, a qualquer hora... neve, inverno, tempestade, Japão, Ásia ou plena Paris.... Você está protegido de tudo quando faz teatro (OLMO, 2015).

Nos conhecemos [se referindo a Serge] no teatro, vivemos no teatro, em apneia. Eu era Ana, ele era Ricardo III; eu era Desdêmona, ele era Otelo; eu era Arkádina, ele era Trigórin (OLMO, 2015).

Apesar de ser um evento com início e fim, pode-se afirmar que a gravidez é apresentada no filme como uma duração. O corpo de Olivia se transforma em um movimento contínuo, sua barriga vai crescendo no fluxo em meio às cenas, sem que haja uma contagem de tempo em meses ou semanas, ou marcos temporais como exames ou a descoberta do sexo. Essa perspectiva contrasta com a visão contemporânea da gravidez como um período de monitoramento (ARNEY apud CHAZAN, 2005).

Arney (apud CHAZAN, 2005), ao pesquisar o contexto britânico e norte-americano, afirma que a profissão da obstetrícia passou por três momentos ao longo da história, que revelam mudanças no entendimento social sobre a gravidez. Até o século XIX, o chamado período pré-profissional, a gestação era vista como um evento caótico e sem controle, classificado pela dicotomia normal/anormal a partir de como o processo se desenvolvia no corpo feminino. A partir do final do século XIX, ocorre a medicalização da gravidez e a formação do campo da obstetrícia, com a retirada das parteiras do processo do nascimento nos Estados Unidos e sua subordinação aos médicos na Inglaterra. Neste período denominado profissional, que se estende até meados do século XX, a gravidez passa a ser vista como potencialmente patológica, e o corpo da mulher é extremamente medicalizado, enxergado apenas como um vetor da gestação, passando a ser alvo de técnicas marcadas pelo forte intervencionismo.

Já desde meados do século XX, vivemos o período de monitoramento (ARNEY apud CHAZAN, 2005), em que a gestação passa a ser enxergada a partir da lógica do risco (VAZ, 1999), que marca as sociedades de controle (DELEUZE, 2013). Ou seja, ela constitui um processo que deve ser minunciosamente vigiado desde o seu início, com o auxílio de diversos dispositivos visuais e laboratoriais, como a ultrassonografia ${ }^{3}$ e os exames sanguíneos

\footnotetext{
${ }^{3}$ Em sua tese de doutorado, Chazan (2005) mostra como a ultrassonografia se revela um produto a ser consumido como espetáculo, a partir de um estudo etnográfico realizado em clínicas de imagem.
} 
periódicos. Para que essa gravidez seja monitorada com êxito, é preciso espacializar o mais minunciosamente possível seu tempo de extensão, contando-a em semanas, acompanhando o desenvolvimento do bebê a partir das expectativas de normalidade de cada estágio. Como resume Rezende (2011, p. 325):

A gestação também passa a ser uma condição médica, controlada por um saber especializado e cuidada através de consultas médicas e vários exames para monitorar a saúde do feto e da gestante Ao contrário de outras sociedades e épocas, a gravidez deixa de ser vista, em larga medida, como um processo "natural" do corpo para ser um que necessita de intervenção e controle médicos.

Bergson (1999) permite pensar a gravidez para além de um fenômeno puramente material - as transformações do corpo feminino. A partir do conceito de duração e da forma como a gestação de Olivia é retratada no filme, é possível questionar a perspectiva medicalizada contemporânea sobre a gravidez e pensá-la a partir de um estranhamento, entendendo-a como um fenômeno no tempo.

Para além da gravidez, a discussão da temporalidade em Olmo e a gaivota é também expressa em um contraponto interessante entre os dois personagens principais. $\mathrm{O}$ tempo em fluxo de Olivia é contraposto, em diversos momentos, ao tempo espacializado de Serge. É a ele que ela recorre quando precisa contabilizar a temporalidade que experimenta como sensação. Em uma cena, ela lhe pede que ajude a contar quantos dias já haviam se passado sem que ela saísse de casa (eram vinte e dois). Enquanto o tempo dele é marcado pelo relógio ("tenho um compromisso às seis"; "foi um longo dia"), o dela é contínuo e entremeado por afetos (o medo diante da expectativa da maternidade enquanto experiência desconhecida e da perda da carreira, o tédio diante das atividades cotidianas...).

Em um diálogo encenado, dirigido por Petra Costa, essa diferença de temporalidade fica evidente. Serge chega do trabalho e se senta diante do computador, mexendo em algumas correspondências. Olivia o interroga sobre o ensaio, querendo saber que atriz está interpretando seu antigo papel. Serge responde, mas desconversa, perguntando: "Não pagamos a conta de luz?". Olivia insiste, até que ele a interpela, perdendo a paciência: “Eu mal acabei o dia, eu não posso...”. A forma que Olivia encontra para chamar a atenção do companheiro para suas necessidades afetivas é traduzindo sua vivência na temporalidade especializada do mundo do trabalho, em que ele vive: "Faz quatro meses que estou presa aqui, assim, nessa posição" (OLMO, 2015). 
Serge afirma que não se sentirá culpado por trabalhar e mede a importância de seu tempo pelo fato de ele ser remunerado: "Ganho 1800 euros por mês, trabalho muito. Quanto você recebe, 20 euros por dia em benefícios? O que a gente faz com isso? Tenho que trabalhar pelo menos 10 horas por dia. Temos contas para pagar, aluguel de 1450 euros por mês, Olivia..." (OLMO, 2015). O tempo de Serge - que corresponde à temporalidade contemporânea do mundo do trabalho - é dividido em fatias e monetizado. Após uma intervenção da diretora, o diálogo prossegue e Serge pergunta a Olivia, de forma mais amena, o que ela havia feito durante o dia. Ela responde de forma poética: "Eu terminei as orelhas. Talvez eu tenha até feito cílios. Acho que acabei o fígado. Mas me tomou muita energia" (idem). O "fazer o bebê" aparece, em sua fala, como uma ação desenvolvida na duração.

Por fim, na parte derradeira do filme, Olivia e Serge preparam e oferecem uma festa aos amigos da atriz. A gravidez vivida na solidão do apartamento é festejada em conjunto na última cena do documentário. Interrogada pelo companheiro sobre o motivo que a fez pensar na comemoração, Olivia afirma: "Se eu não compartilhar esse momento com pessoas que são... que são porque foram fundamentais, é como se eu não estivesse grávida" (OLMO, 2015, grifo meu). Nesse diálogo, Olivia resgata as pessoas que marcaram sua vida para que elas possam ajudá-la, percebendo-a como uma mulher em gestação. Sua percepção de si mesma, atravessada pela memória do foi construído e vivido nessas relações, abre uma dobra entre um presente e um passado que coexistem em sua experiência vivida.

Assim, a percepção de outras pessoas é capaz de agir na própria forma com que Olivia elabora seu presente e as dificuldades enfrentadas na gravidez, em um momento em que sua atenção à vida a guia para o futuro iminente do parto e a concretização da maternidade. A festa representa essa confluência entre passado, presente e futuro, que convergem e se misturam na duração.

\section{CONSIDERAÇÕES}

A partir da discussão empreendida neste artigo, observamos como o filme Olmo e a gaivota exibe, a partir de sua narrativa sobre a gravidez, uma reflexão sobre a temporalidade, adensada teoricamente a partir da perspectiva de Bergson (1999). A gestação da personagem principal, a atriz Olivia Corsini, pode ser pensada como uma duração, ao constituir um tempo contínuo e indivisível, um fluxo que não cessa de passar. Essa perspectiva, percebida na forma como as cenas e os diálogos são estruturados e realizados, contraria a visão 
contemporânea da gravidez como um período de monitoramento (ARNEY apud SHAZAN, 2005), que deve ser quantificado e dividido em fatias temporais para que seja minunciosamente vigiado e medicalizado.

A filosofia de Bergson acerca do tempo também apresenta uma base sólida para questionar a temporalidade hegemônica da vida contemporânea, expressa na ideia do tempo 24/7 (CRARY, 2013), em que a vida deve ser experimentada de forma acelerada, sem pausas, e convertida em ganhos financeiros. No filme, o contraponto entre o tempo financializado de Serge, que vive no mundo do trabalho, e de Olivia, que experimenta a gravidez como duração, revela o quanto o hábito de espacializar o tempo e orientá-lo unicamente para a produção não dá conta dos matizes que circundam a experiência humana da temporalidade. Além disso, ao narrar-se a partir do ponto de vista da mulher gestante, tomando seu corpo como centro de ação, o filme contribuiu para representar a gestação como uma experiência subjetiva complexa, modulada por afetos e contradições.

Por fim, o filme Olmo e a gaivota apresenta uma perspectiva instigante não só sobre a gravidez - que encontra pouca representatividade no cinema - mas também sobre o tempo. Desse modo, a perspectiva de Bergson se revela extremamente fértil para compreender essa obra contemporânea e suas relações com a cultura, assim como o filme oferece uma janela oportuna para refletir como a concepção bergsoniana de duração e seu pensamento acerca da percepção e das afecções humanas fundam uma perspectiva filosófica fundamental para compreender o modo como experimentamos o tempo e a forma como o inventamos em produtos culturais como o cinema.

\section{REFERÊNCIAS}

BERGSON, Henri. Matéria e memória: ensaio sobre a relação do corpo com o espírito. São Paulo: Martins Fontes, 1999.

CHAZAN, Krakowski Lilian. "Meio quilo de gente!" - Produção do prazer de ver e construção da pessoa fetal mediada pela ultrassonografia: um estudo etnográfico em clínicas de imagem na cidade do Rio de Janeiro. Tese de Doutorado. Instituto de Medicina Social da Universidade do Estado do Rio de Janeiro, 2005.

CRARY, Jonathan. 24/7: late capitalism and the ends of sleep. Londres: Verso, 2013.

DELEUZE, Gilles. Bergsonismo. São Paulo: Editora 34, 1999.

. Post-scriptum sobre as sociedades de controle. In: DELEUZE, Gilles. Conversações (19721990). São Paulo: Editora 34, 2013, p. 223-230. 
FERRAZ, Maria Cristina Franco. Afeto e comunicação: das construções do medo. In: Anais do XXV Encontro Anual da Compós, Universidade Federal de Goiás. Goiânia: Compós, 2016.

FOUCAULT, Michel. A ordem do discurso. São Paulo: Loyola, 2011

OLMO E A GAIVOTA. Direção: Petra Costa; Lea Glob. [S.1.]: Zentropa Entertainments5; Busca Vida Filmes; O Som e a fúria, 2015. 1 DVD (85 min).

PLATÃO. A república - Parte II. São Paulo: Escala, 2007.

REZENDE, Claudia Barcellos. Um estado emotivo: representação da gravidez na mídia. Pagu, v. 36, janeiro-junho 2011, p. 315-344.

ROCHA, Everardo. A sociedade do sonho: comunicação, cultura e consumo. Rio de Janeiro: Mauad $\mathrm{X}, 2012$.

TUCHERMAN, Ieda. Usos e abusos da leitura de Proust: reflexões em torno de Como Proust pode mudar sua vida (Alain de Botton) e Proust e os signos (Gilles Deleuze). Logos, v. 23, n.2, 2016, p. 91 102.

VAZ, Paulo. Corpo e Risco. Forum Media, Viseu, v. 1, n.1, p. 101-111, 1999.

Original recebido em: 08 de maio de 2017

Aceito para publicação em: 29 de agosto de 2019

Tatiane Leal

Doutora e Mestre em Comunicação pela Universidade Federal do Rio de Janeiro (ECOUFRJ), onde também se graduou como jornalista. Foi professora substituta da Graduação em Comunicação Social da ECO-UFRJ. É vice-coordenadora do Núcleo de Estudos de Mídia, Emoções e Sociabilidade (NEMES) e autora de publicações na área de gênero e mídia. Atualmente realiza o pósdoutorado no Instituto Nacional de Comunicação Pública da Ciência e Tecnologia (INCT-CPCT), vinculado à Fundação Oswaldo Cruz (FIOCRUZ), com bolsa da Fundação Carlos Chagas Filho de Amparo à Pesquisa do Estado do Rio de Janeiro (FAPERJ).

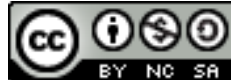

Esta obra está licenciado com uma Licença Creative Commons Atribuição-NãoComercial-CompartilhaIgual 4.0 Internacional 